\title{
Influence of Surface Treatments on the Bioactivity of Ti
}

\author{
Carl Lindahl, ${ }^{1,2}$ Håkan Engqvist,, ${ }^{1,2}$ and Wei Xia ${ }^{1,2}$ \\ ${ }^{1}$ Applied Materials Science, Department of Engineering Sciences, Uppsala University, 75121 Uppsala, Sweden \\ ${ }^{2}$ BIOMATCELL, VINN Excellence Center of Biomaterials and Cell Therapy, University of Gothenburg, 40530 Gothenburg, Sweden
}

Correspondence should be addressed to Wei Xia; wei.xia@angstrom.uu.se

Received 22 November 2012; Accepted 10 December 2012

Academic Editors: S.-J. Ding and M. Rouabhia

Copyright (c) 2013 Carl Lindahl et al. This is an open access article distributed under the Creative Commons Attribution License, which permits unrestricted use, distribution, and reproduction in any medium, provided the original work is properly cited.

\begin{abstract}
Several techniques have been described to modify the surface of titanium to make it more bioactive. Heat treatment (HT) and sodium hydroxide treatment $(\mathrm{NaOH})$ have been used and can change the crystallinity and surface chemistry of titanium implants. However, no studies have systemically focused on comparing these different methods and their effect on the bioactivity of Ti. Therefore, in this study, Ti substrates were systematically treated using $\mathrm{HT}, \mathrm{NaOH}$, and a combination of $\mathrm{HT}$ and $\mathrm{NaOH}$. The Ti plates were heat treated at various temperatures, and the plates were subjected to HT followed by soaking in $\mathrm{NaOH}$ or first soaked in $\mathrm{NaOH}$ and then heat treated. The morphology, crystallinity, hardness, water contact angle, and surface energy of the samples were analyzed as well as the bioactivity after immersion in PBS. Morphology and crystallinity changed with increasing temperature. The difference was most pronounced for the $800^{\circ} \mathrm{C}$ treated samples. The water contact angle decreased, and the surface energy increased with increasing temperature and was highest for $800^{\circ} \mathrm{C}$. The rutile surface showed faster hydroxyapatite formation. $\mathrm{NaOH}$ treatment of the HT Ti samples increased the surface energy and improved its bioactivity further. Also, $\mathrm{HT}$ of $\mathrm{NaOH}$ samples improved the bioactivity compared to only HT.
\end{abstract}

\section{Introduction}

Titanium has become a well-established material in orthopedic and dental applications because of its biocompatibility, strength, and corrosion resistance [1-3]. One of the key reasons for Ti's ability to be tolerated and integrated into bone tissue is its surface properties, which is mainly correlated to the thin titanium oxide surface layer that forms spontaneously in air [4]. But there is room for continued improvement of Ti's stability in host tissue, for example, via surface treatments to enhance the positive effect of the surface oxide. Several techniques have been used to modify the surface of titanium to increase its bone integration or even produce a bioactive surface (to promote bone bonding) [5-8]. Examples of such methods include acid etching of the Ti surface to enhance the surface roughness and coating the titanium substrate with a hydroxyapatite to form a surface that is similar to bone tissue $[6,7,9]$. One coating technique used for both bioactivity testing and HA coating method is the biomimetic process developed by Uchida et al. [8].

Bioactivity of a material is defined as the ability to form a chemical bond to bone in vivo [10]. In Kokubo's method, an implant material is soaked in a simulated body fluid (SBF) at $37^{\circ} \mathrm{C}$ for up to four weeks. The simulated body fluid is supersaturated towards hydroxyapatite formation. If hydroxyapatite forms on the surface within the four weeks period, the implant material is deemed to be bioactive. It has been later proven that in essence, a bioactive material has a negative surface charge in the SBF solution that in turn promotes the formation of hydroxyapatite on/at the surface.

The natural titanium oxide that forms spontaneously on $\mathrm{Ti}$ is negatively charged at $\mathrm{pH}$ 7.4. The Ti-OH groups on the surface become deprotonated when immersed in SBF solutions to form negatively charged groups [11]. And there are different methods to enhance the negative charge on titanium surface further, for example, formation of a crystalline titanium oxide and chemical treatments $[9,12]$. For chemical treatments, a common method is to produce a sodium titanate layer on its surface via soaking the Ti implant material in a high concentration $\mathrm{NaOH}$ solution. The treatment of titanium with sodium hydroxide produces a fine network structure of nanometer scale on the surface of the titanium metal [13]. Surface oxidation using heat treatment (HT) and plasma immersion is commonly used to increase 


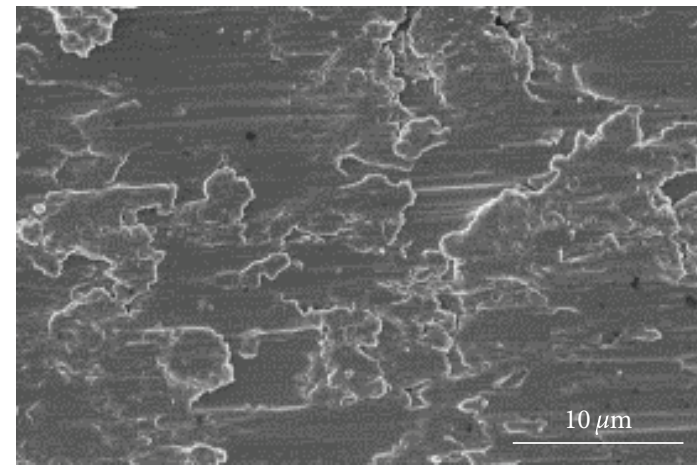

(a)

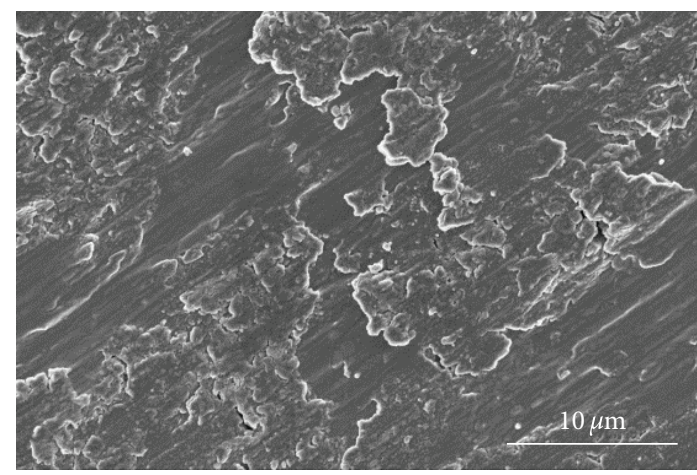

(c)

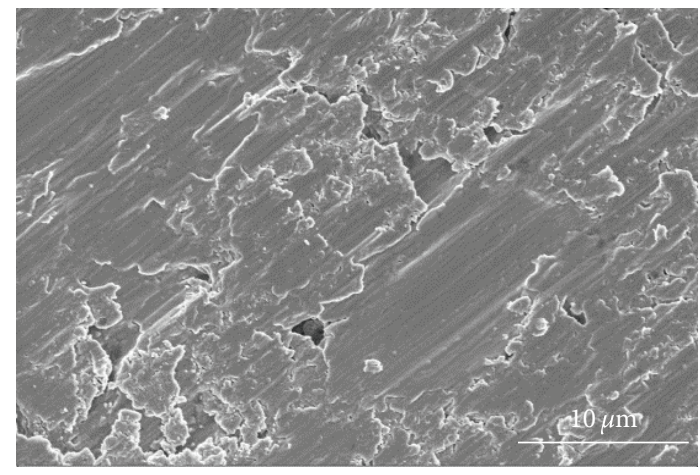

(b)

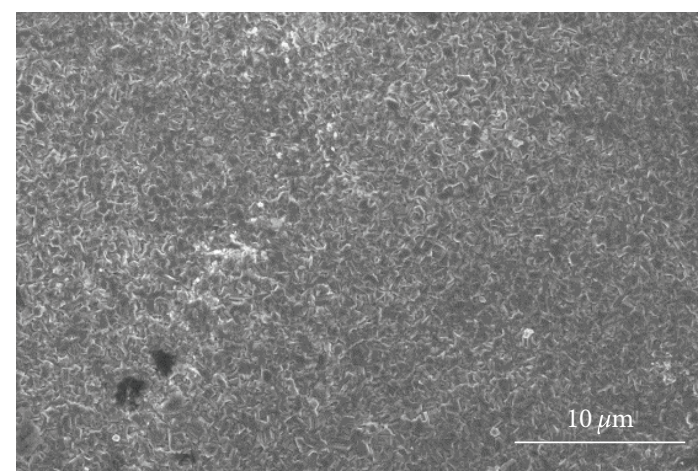

(d)

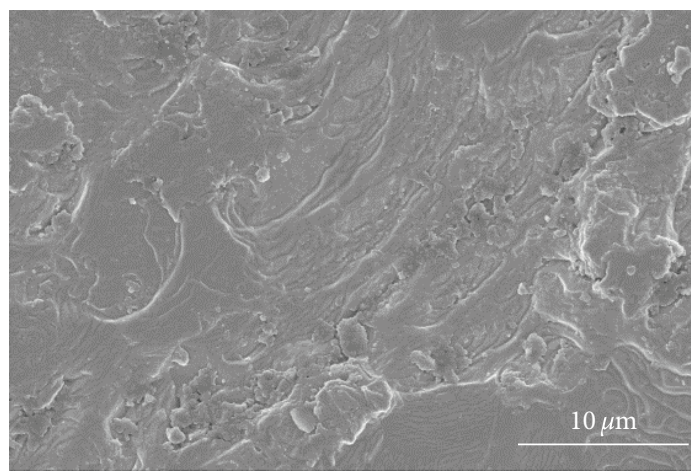

(e)

Figure 1: Ti subjected to heat treatments. (a) HT200, (b) HT300, (c) HT500, (d) HT800, and (e) Ti.

the crystallinity of the titanium oxides. Combined sodium hydroxide soaking and HT has previously been applied to a porous titanium layer on a hip implant and has been used clinically in Japan since 2007 [14]. This treatment produces a surface roughness on the nanometer scale with high specific surface area and has been found to release no ions in vivo [13]. The role of the oxide layer on the chemical and biological properties of titanium has been demonstrated in several studies [15-18]. The oxide layer also has an important role in the adsorption of proteins and calcium and phosphate ions on the surface of titanium in vivo [19]. Oxide thickness and porosity have been shown to have a strong effect on the in vivo performance.
There are several studies in the literature that compares the influence of different surface treatments of $\mathrm{Ti}$ on the bioactivity [19-28]. The influence of thermal treatment and different solution treatments on the bioactivity has been tested. However, no studies have systematically compared the differences in bioactivity of nontreated Ti, heat treatment $\mathrm{Ti}$, sodium hydroxide treatment $\mathrm{Ti}$, or a combination of these treatments of $\mathrm{Ti}$ on the bioactivity. Therefore, to obtain more knowledge about the influence of bioactivity of Ti, a systematic evaluation of the different treatments is needed. In this study, we systematically compare different treatments of titanium that are commonly used. The surface morphology and surface energy of the $\mathrm{Ti}$ surface treated with these 


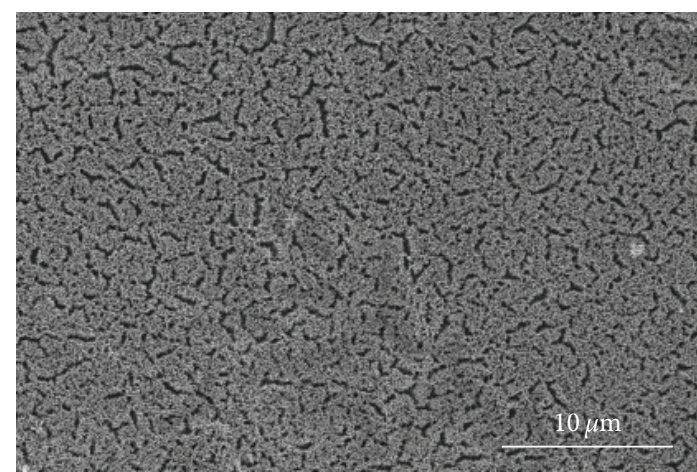

(a)

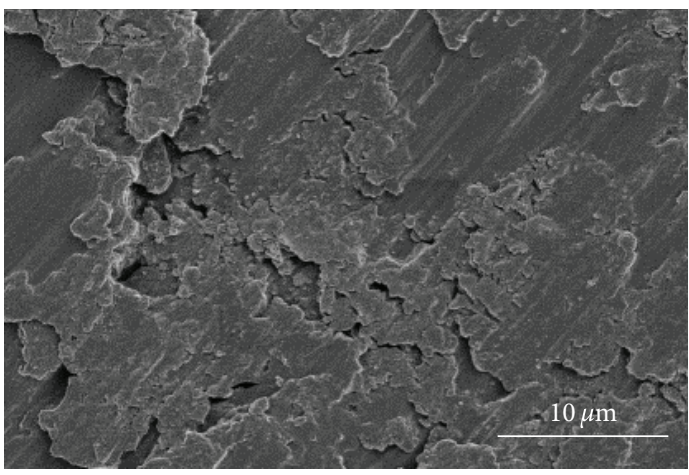

(c)

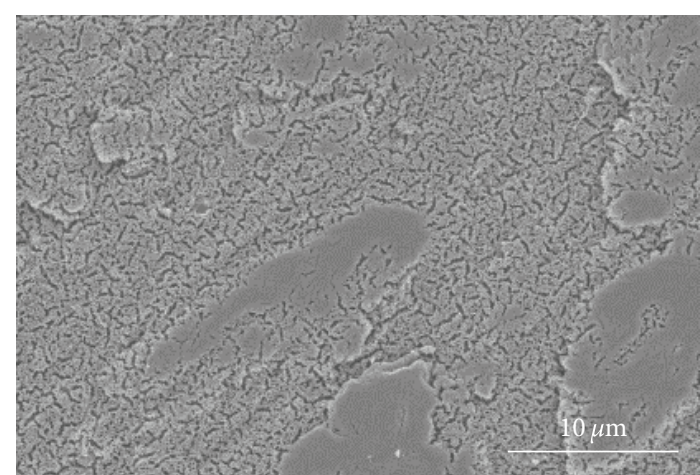

(b)

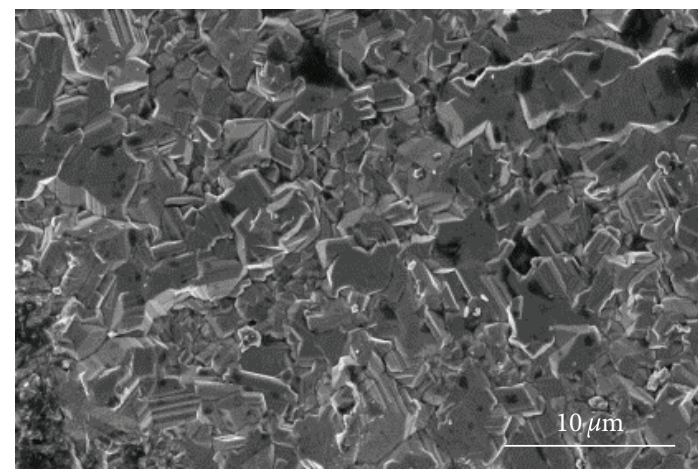

(d)

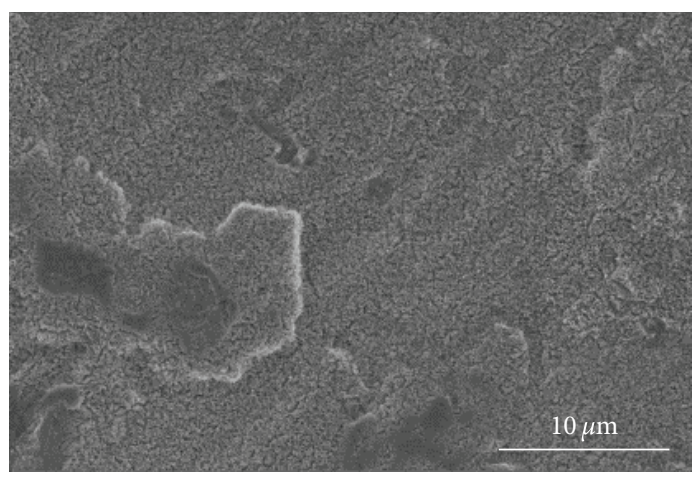

(e)

Figure 2: Ti subjected to heat treatment followed by NaOH treatment. (a) HT200-NaOH, (b) HT300-NaOH (c) HT500-NaOH, (d) HT800$\mathrm{NaOH}$, and (e) Ti-NaOH.

different methods is evaluated. Finally, the HA formation (in vitro bioactivity) on the surfaces subjected to these different treatments as function of soaking time is investigated.

\section{Materials and Methods}

2.1. Sample Preparation. Titanium grade 2 plates, size $10 \times$ $10 \times 1 \mathrm{~mm}$, were prepared according to different treatment groups; see Table 1. Sodium hydroxide pellets were purchased from Sigma Aldrich (USA). These $\mathrm{NaOH}$ pellets were dissolved in deionized water to obtain a $5 \mathrm{M} \mathrm{NaOH}$ solution. Ti control samples were compared to only $\mathrm{NaOH}$ soaking, only HT from 200 to $800^{\circ} \mathrm{C}$, and combinations of HT followed by
$\mathrm{NaOH}$ soaking or $\mathrm{NaOH}$ soaking followed by HT. Prior to the treatments, the samples were cleaned in acetone, ethanol, and deionized water for $15 \mathrm{~min}$, respectively, and dried at $37^{\circ} \mathrm{C}$ prior to analysis. The HT of the Ti substrates was performed at the different temperatures for $1 \mathrm{~h}$ holding time with a ramping rate of $5^{\circ} \mathrm{C} / \mathrm{min}$.

2.2. Bioactivity Testing. For testing the bioactivity, the samples were immersed in Dulbecco's phosphate buffer saline solution (PBS, Aldrich, USA) for different time periods, 1 day, 4 days, and 7 days, at $37^{\circ} \mathrm{C}$. Afterwards, the samples were gently cleaned in deionized water and dried at $37^{\circ} \mathrm{C}$ prior to analysis. 


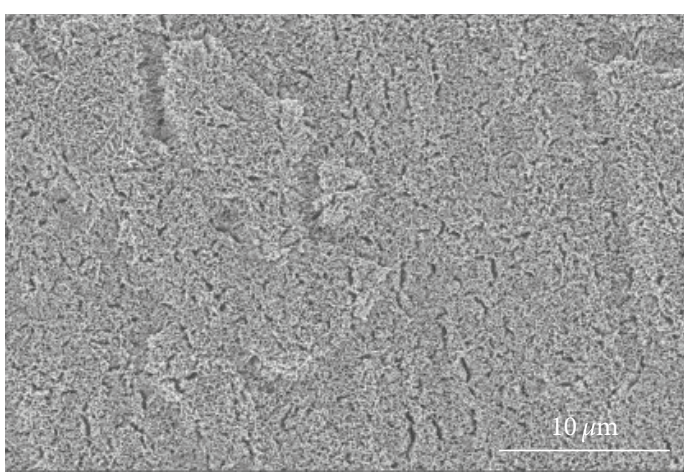

(a)

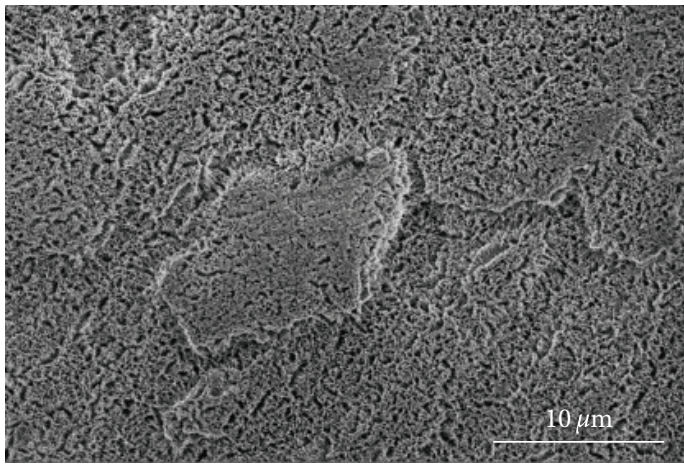

(c)

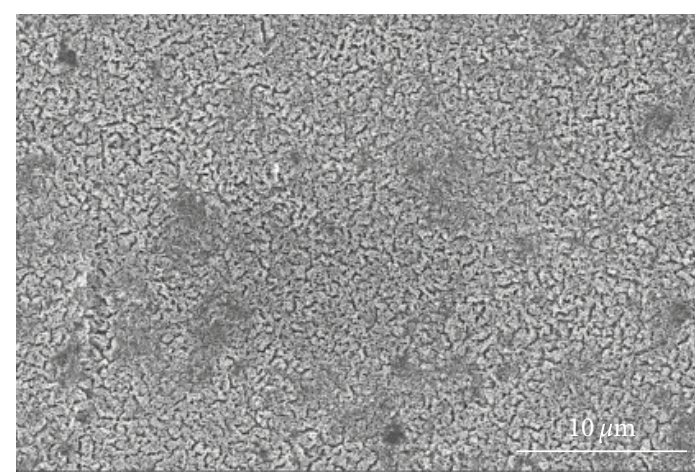

(b)

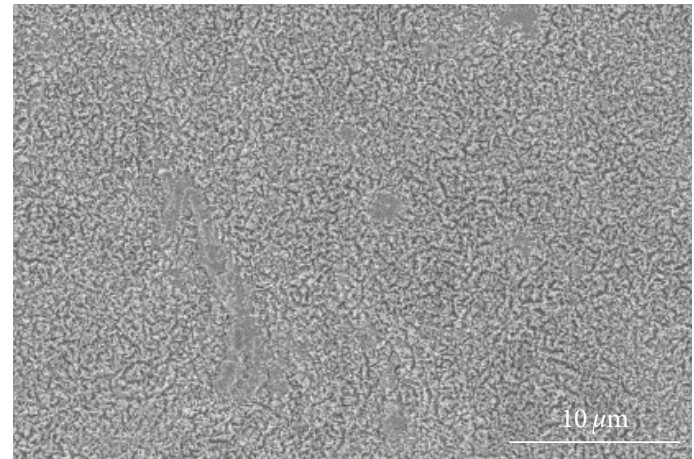

(d)

Figure 3: Ti subjected to $\mathrm{NaOH}$ treatment followed by heat treatment. (a) NaOH-HT200, (b) NaOH-HT300, (c) NaOH-HT500 and (d) $\mathrm{NaOH}-\mathrm{HT} 800$.

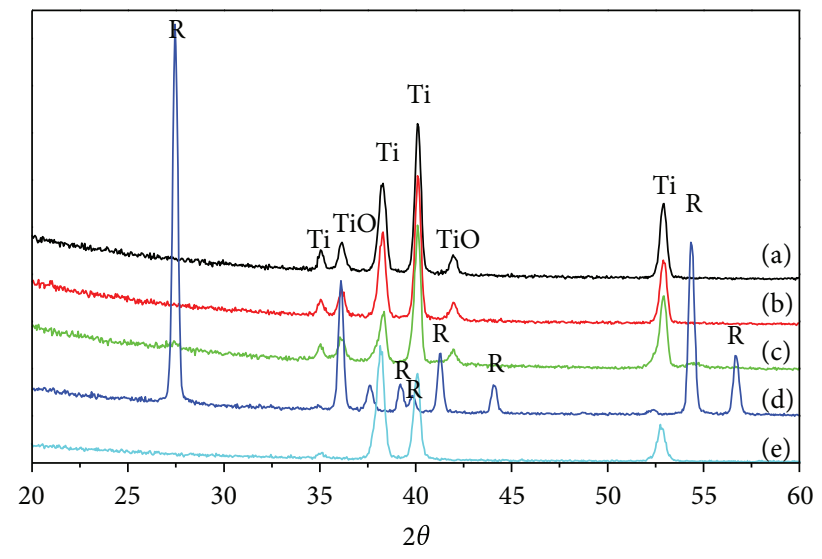

FIGURE 4: XRD patterns of titanium plates subjected to HT alone, group II. (a) HT200, (b) HT300, (c) HT500, (d) HT800, and (e) Ti. (R: rutile; TiO: titanium oxide; Ti: titanium.)

\subsection{Analysis}

2.3.1. Surface Morphology and Crystallinity. The influence on the morphology of the Ti surface due to different surfaces treatments was analyzed by scanning electron microscopy (SEM, LEO 1550-SEM). SEM was also used to check the morphology of the surfaces after immersion in PBS solution.

X-ray diffraction analysis (XRD) (D5000, Siemens) using $\mathrm{Cu} \mathrm{K} \alpha$ radiation $(\lambda=1.5418 \AA)$ was used to evaluate the crystallinity of the samples after the different treatments

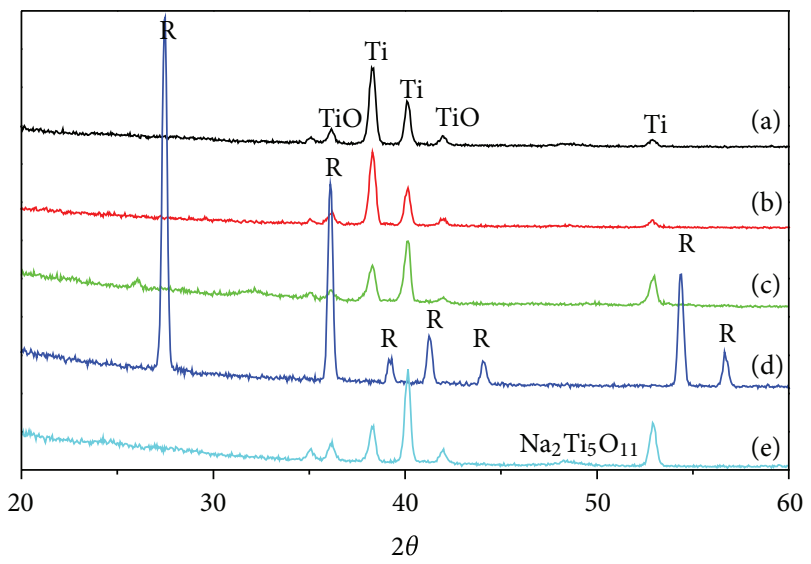

FIGURE 5: XRD patterns of titanium plates subjected to HT followed by $\mathrm{NaOH}$ soaking, group III. (a) HT200-NaOH, (b) HT300-NaOH, (c) HT500-NaOH, (d) HT800-NaOH, and (e) Ti-NaOH. (R: rutile; TiO: titanium oxide; Ti: titanium; $\mathrm{Na}_{2} \mathrm{Ti}_{5} \mathrm{O}_{11}$ : sodium titanate.)

as well as after immersion in PBS. An FTIR (Bruker IFS $66 \mathrm{v} / \mathrm{s}$ FTIR with an MCT detector that was $\mathrm{LN}_{2}$ cooled) with a equipped ATR cell was also used to characterize the samples after immersion in PBS. Nontreated Ti was used as background.

2.3.2. Hardness Measurements. To study the influence of surface treatments on the hardness of the samples, hardness 


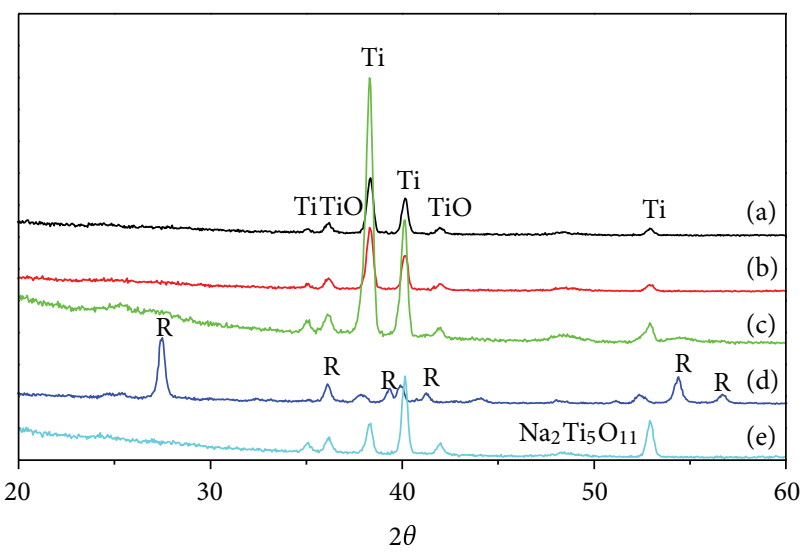

FIgURE 6: XRD patterns of titanium plates subjected to $\mathrm{NaOH}$ soaking followed by HT, group IV. (a) NaOH-HT200, (b) $\mathrm{NaOH}-$ HT300, (c) NaOH-HT500, (d) NaOH-HT800, and (e) Ti-NaOH. (R: rutile; TiO: titanium oxide; Ti: titanium; $\mathrm{Na}_{2} \mathrm{Ti}_{5} \mathrm{O}_{11}$ : sodium titanate.)

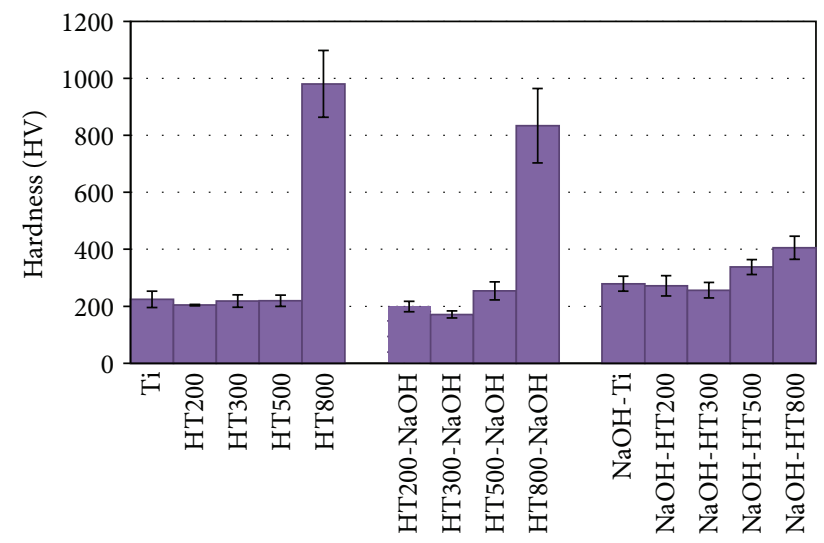

FIgURE 7: Hardness measurements of Ti plates subjected to different treatments (load: $100 \mathrm{~g}$ ).

TABLE 1: Surface treatments used in this study.

\begin{tabular}{ll}
\hline Treatments & Treatments process \\
\hline Ti (control) & Untreated \\
I & $5 \mathrm{M} \mathrm{NaOH}$ soaking at $60^{\circ} \mathrm{C}$ for $24 \mathrm{~h}$ \\
II & Heat treatment at $200^{\circ} \mathrm{C}, 300^{\circ} \mathrm{C}, 500^{\circ} \mathrm{C}$, or \\
& $800^{\circ} \mathrm{C}$ for $1 \mathrm{~h}$ \\
& Heat treatment at $200^{\circ} \mathrm{C}, 300^{\circ} \mathrm{C}, 500^{\circ} \mathrm{C}$, or \\
III & $800^{\circ} \mathrm{C}$ for $1 \mathrm{~h}$ followed by $5 \mathrm{M} \mathrm{NaOH}$ soaking at \\
& $60^{\circ} \mathrm{C}$ for $24 \mathrm{~h}$ \\
& $5 \mathrm{M} \mathrm{NaOH}$ soaking at $60^{\circ} \mathrm{C}$ for $24 \mathrm{~h}$ followed by \\
IV & heat treatment at $200^{\circ} \mathrm{C}, 300^{\circ} \mathrm{C}, 500^{\circ} \mathrm{C}$, or \\
& $800^{\circ} \mathrm{C}$ for $1 \mathrm{~h}$ \\
\hline
\end{tabular}

measurements were performed. Hardness of the titanium plates before and after the different treatments was evaluated using the Vickers microhardness tester. The load used was $100 \mathrm{~g}$.

2.3.3. Contact Angle Measurements. The wettability of the different surfaces was analyzed by measuring the water contact angle. The measurements were performed using the

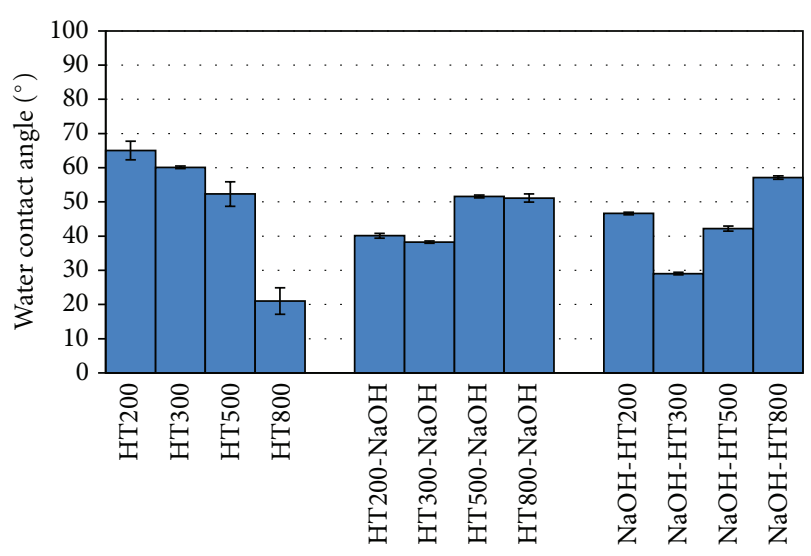

FIGURE 8: Water contact angle for different treatments of titanium oxide surfaces.

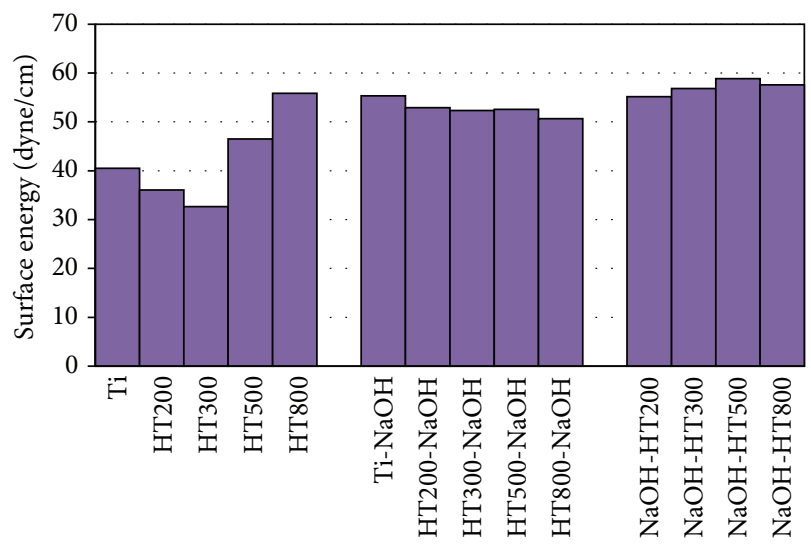

FIgURE 9: Surface energy for different treatments of titanium surfaces.

software Dataphysics OCA 20. The surface energy of the Ti surfaces before and after treatment were also calculated using an equation that shows the relationship between the surface energy components, liquid components, and contact angle [29] as follows:

$$
\Upsilon_{L}(1+\cos \theta)=2\left\{\sqrt{\Upsilon_{S}^{d}+\Upsilon_{L}^{d}}+\sqrt{\Upsilon_{S}^{+}+\Upsilon_{L}^{-}}+\sqrt{\Upsilon_{L}^{+} \Upsilon_{S}^{-}}\right\},
$$

where $\Upsilon_{S}^{d}$ is the dispersive component, and $\Upsilon_{S}^{+}, \Upsilon_{S}^{-}$are the polar components.

From this equation, the surface energy can be calculated by dispersing drops of three known liquids. In this study, three liquids were used: water, diiodomethane, and formamide [30-32].

\section{Results}

3.1. Surface Properties. The surface thermally oxidized at $800^{\circ} \mathrm{C}$ showed the most difference in morphology compared to the lower temperatures; see Figure 1. There was a marked difference between the samples soaked in $\mathrm{NaOH}$ first and then HT (group IV) and group III that was first heat treated 


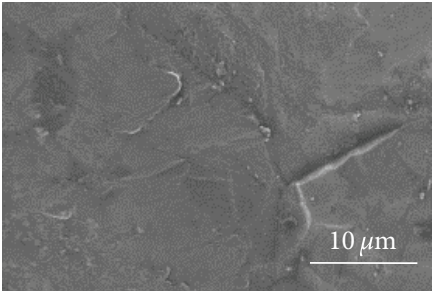

(a)

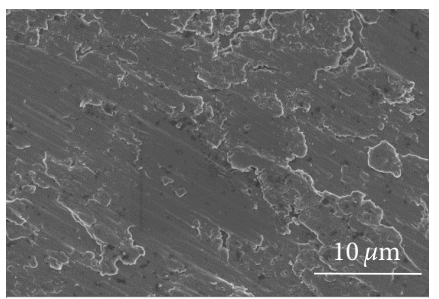

(d)

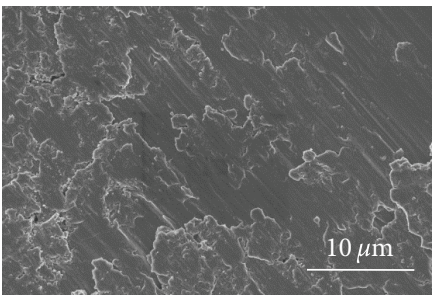

(g)

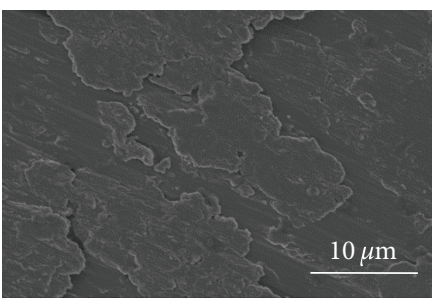

(j)

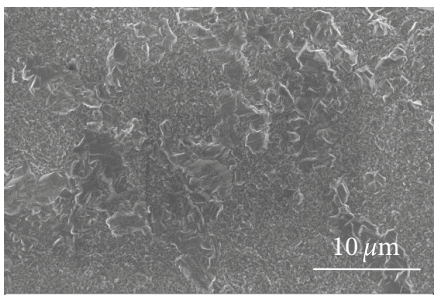

(m)

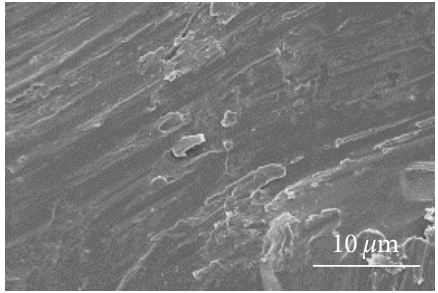

(b)

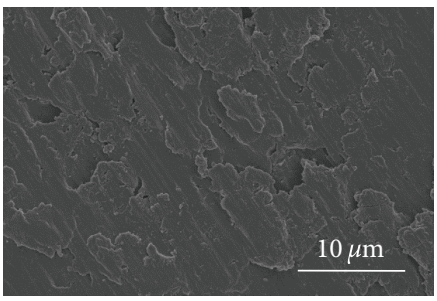

(e)

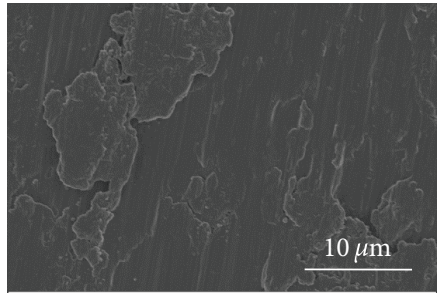

(h)

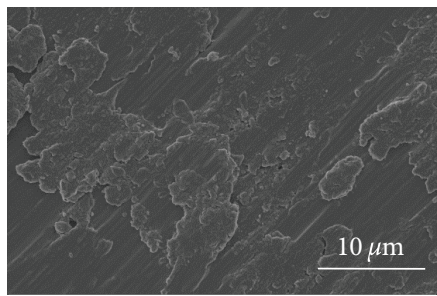

(k)

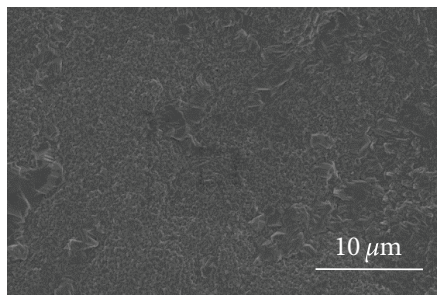

(n)

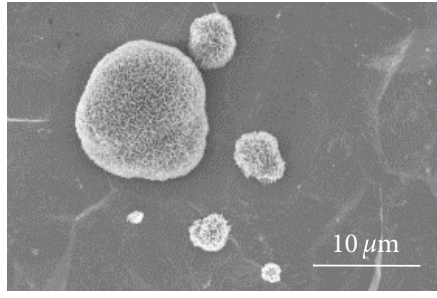

(c)

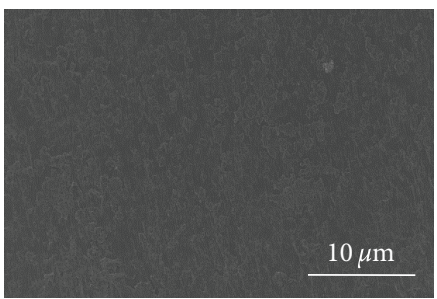

(f)

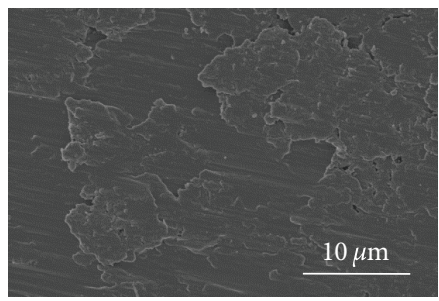

(i)

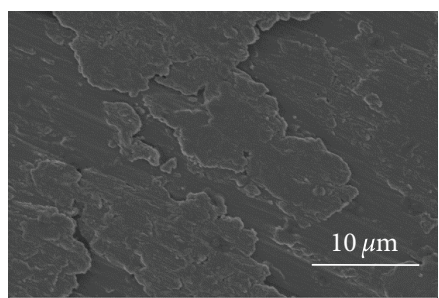

(1)

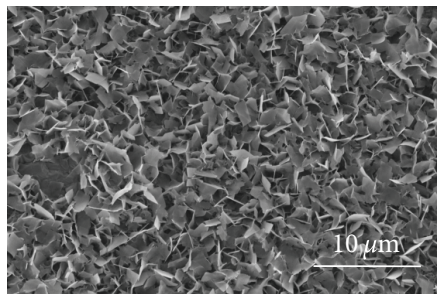

(o)

Figure 10: Ti subjected to different heat treatments (group II) and soaked in PBS at $37^{\circ} \mathrm{C}$ for 1 day, 4 days, and $7 \mathrm{days}$. (a) Ti $1 \mathrm{~d}$, (b) Ti $4 \mathrm{~d}$, (c) Ti 7 d, (d) $200 \mathrm{HT} 1 \mathrm{~d}$, (e) 200HT 4 d, (f) 200HT 7 d, (g) 300HT 1 d, (h) $300 \mathrm{HT} 4$ d, (i) 300HT 7 d, (j) 500HT 1 d, (k) $500 \mathrm{HT} 4 \mathrm{~d}$, (l) $500 \mathrm{HT}$ $7 \mathrm{~d},(\mathrm{~m}) 800 \mathrm{HT} 1 \mathrm{~d},(\mathrm{n}) 800 \mathrm{HT} 4 \mathrm{~d}$, and (o) $800 \mathrm{HT} 7 \mathrm{~d}$.

and then soaked; compare Figures 2 and 3. The $\mathrm{NaOH}$ soaked surfaces show a porous gel-type of surface structure. For higher temperatures, the thicker oxide layer formed seemed to hinder the formation of the porous structure; see Figure 2. For surfaces that first formed, the porous $\mathrm{NaOH}$ structure and subsequent subjected to HT did not lead to any significant change in morphology; see Figure 3.

Rutile peaks were observed in the XRD pattern after heat treatment at $800^{\circ} \mathrm{C}$. There were some oxide peaks observed in the patterns for the surfaces treated at the lower temperatures; 


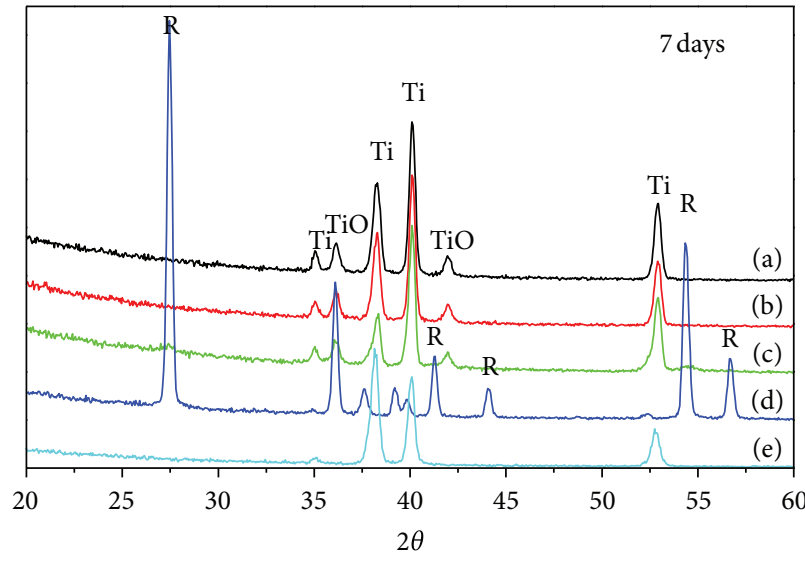

(a)

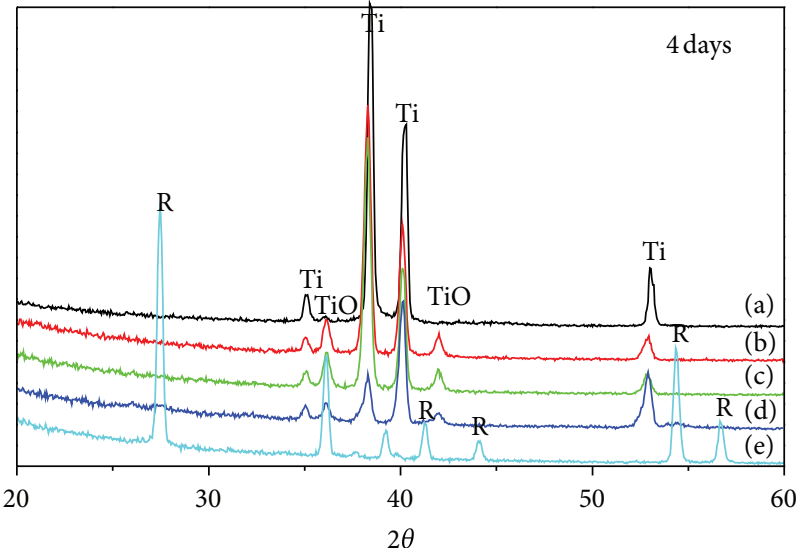

(b)

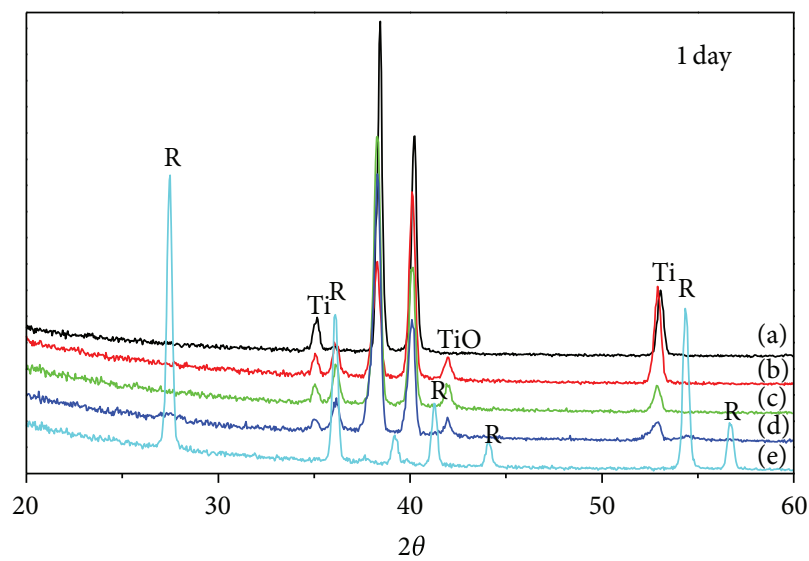

(c)

FIGURE 11: XRD patterns of heat-treated Ti plates (group II) soaked in PBS at $37^{\circ} \mathrm{C}$ for 1 day, 4 days, and 7 days. (a) Ti, (b) HT200, (c) HT300, (d) HT500, and (e) HT800. (Ti: titanium, R: rutile, TiO: titanium oxide.)

see Figures 4, 5, and 6. Sodium titanate $\left(\mathrm{Na}_{2} \mathrm{Ti}_{5} \mathrm{O}_{11}\right)$ peaks were detected for the Ti treated in $5 \mathrm{NaOH}$ solution as well as group IV. Group III did not show any $\mathrm{Na}_{2} \mathrm{Ti}_{5} \mathrm{O}_{11}$ peaks; see Figures 4-6.

The hardness measurements also showed differences depending on surface treatment; see Figure 7. The hardness was highest for $800^{\circ} \mathrm{C}$, and for the samples subjected only to heat treatment, there was no significant difference between Ti, HT200, HT300, and HT500. The overall trend though was increase of hardness with temperature. Interestingly, the hardness for group III was higher than for the other groups, but the marked increase in hardness at $800^{\circ} \mathrm{C}$ was not present; see Figure 7.

The water contact angle decreased with increased temperature for group II; see Figure 8. There was a decrease in water contact angle and an increase in surface energy for groups I, III, and IV compared to group II and the Ti control; see Figures 8 and 9. And the surface energy increased with increased temperature for group II; see Figure 9. Again, group IV behaved differently from the other groups showing a higher surface energy than the other.
3.2. Bioactivity Testing. Bioactivity testing of the samples showed that there was a clear difference in the apatite formation between the different groups. On samples of group II, apatite formation was only observed on the $800^{\circ} \mathrm{C}$ treated surface after 1 week soaking. The $200^{\circ} \mathrm{C}, 300^{\circ} \mathrm{C}$, and $500^{\circ} \mathrm{C}$ surfaces showed no apatite formation; see Figure 10, regardless of the soaking time. This was also confirmed in the XRD analysis; see Figure 11.

The Ti surfaces from group III showed improved apatite formation ability compared to $\mathrm{Ti}$ (control); see Figures 12 and 13. The apatite formation was similar for the group II after 1 day soaking. However, after 4 days soaking, apatite formed on the HT500- NaOH and HT800-NaOH surfaces. All the surfaces were covered by apatite after 1 week soaking in PBS; see Figure 12. Group IV showed the best bioactivity compared to the other groups; see Figures 14 and 15.

No apatite formation was observed after 1 day; see Figures 14(a), 14(d), 14(g), and 14(j). After 4 days soaking, apatite formed only on the NaOH-HT800 surface; see Figures 14(b), 14(e), 14(h), and 14(k). After 1 week soaking, apatite was detected on all the treated surfaces 


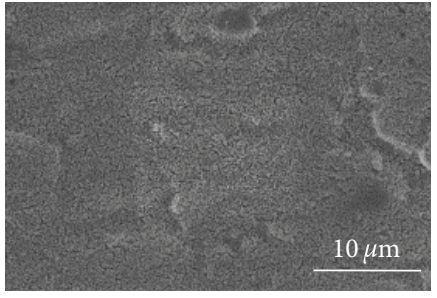

(a)

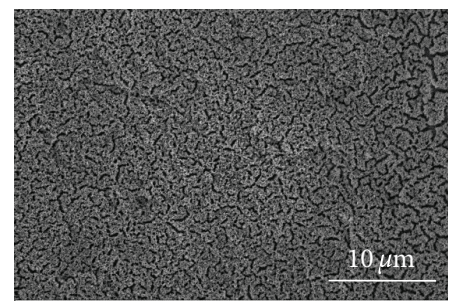

(d)

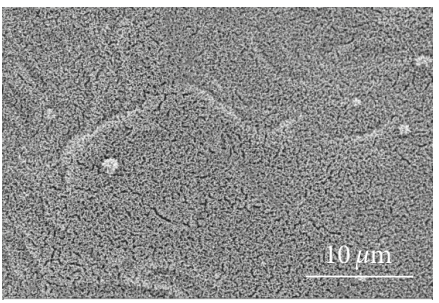

(g)

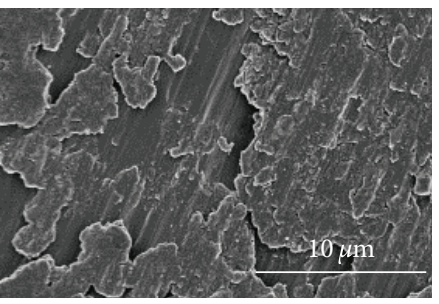

(j)

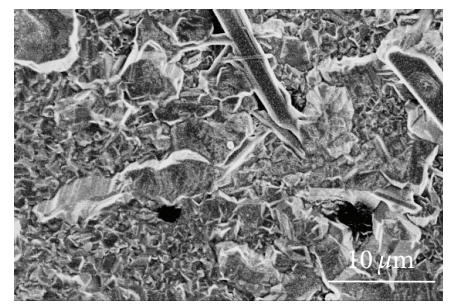

(m)

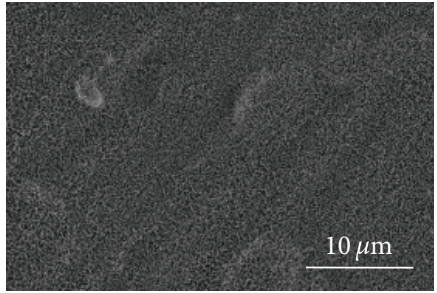

(b)

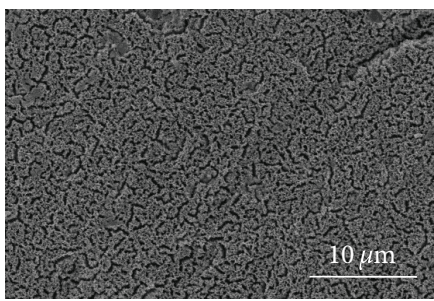

(e)

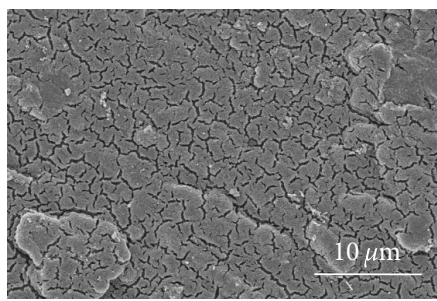

(h)

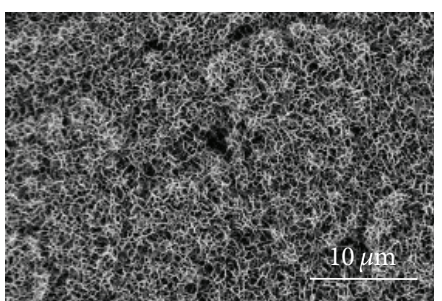

(k)

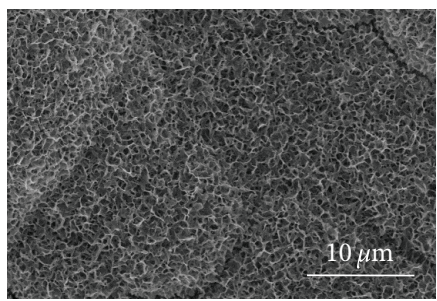

(n)

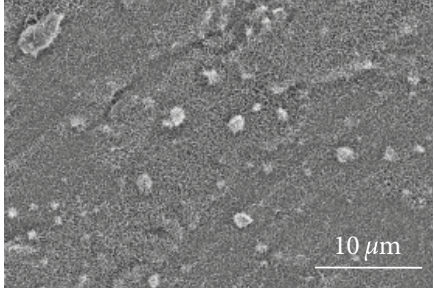

(c)

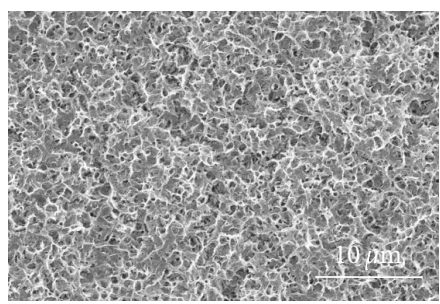

(f)

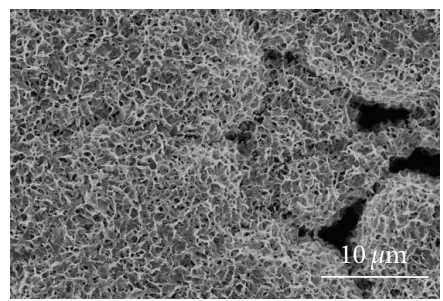

(i)

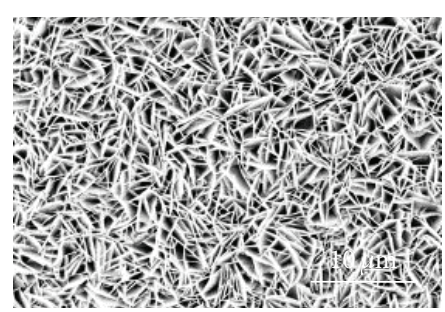

(1)

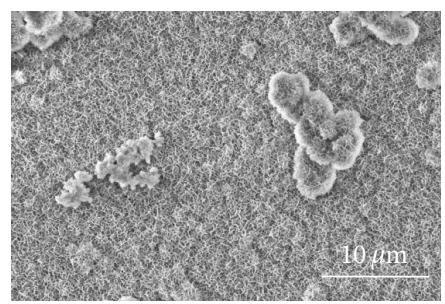

(o)

Figure 12: Ti subjected to HT followed by $\mathrm{NaOH}$ soaking (group III) and subsequently soaked in PBS at $37^{\circ} \mathrm{C}$ for 1 day, 4 days, and 7 days. (a) Ti-NaOH 1 d, (b) Ti-NaOH 4 d, (c) Ti-NaOH 7 d, (d) HT200-NaOH 1 d, (e) HT200-NaOH 4 d, (f) HT200-NaOH 7 d, (g) HT300-NaOH 1 d, (h) HT300-NaOH 4 d, (i) HT300-NaOH 7 d, (j) HT500-NaOH 1 d, (k) HT500-NaOH 4 d, (l) HT500-NaOH 7 d, (m) HT800-NaOH 1 d, (n) HT800-NaOH 4 d, and (o) HT800-NaOH 7 d.

except NaOH-HT500 surface; see Figures 14(c), 14(f), 14(i), and 14(j). Figure 16 shows the FTIR spectra of the samples of $\mathrm{Ti}-\mathrm{NaOH}$ and $\mathrm{HT} 800-\mathrm{NaOH}$, in the wave number range $1200-500 \mathrm{~cm}^{-1}$ which covers the bending and stretching absorption regions of hydroxyapatite. There is no obvious absorption of phosphates for the Ti-NaOH sample. Absorption bands for phosphate were observed at around $1085 \mathrm{~cm}^{-1}$, and the intensity was increased with 


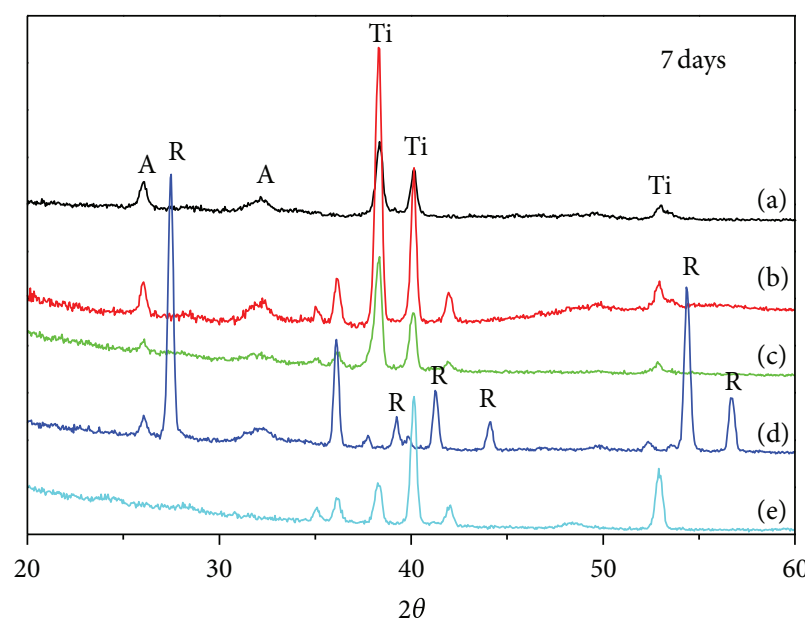

(a)

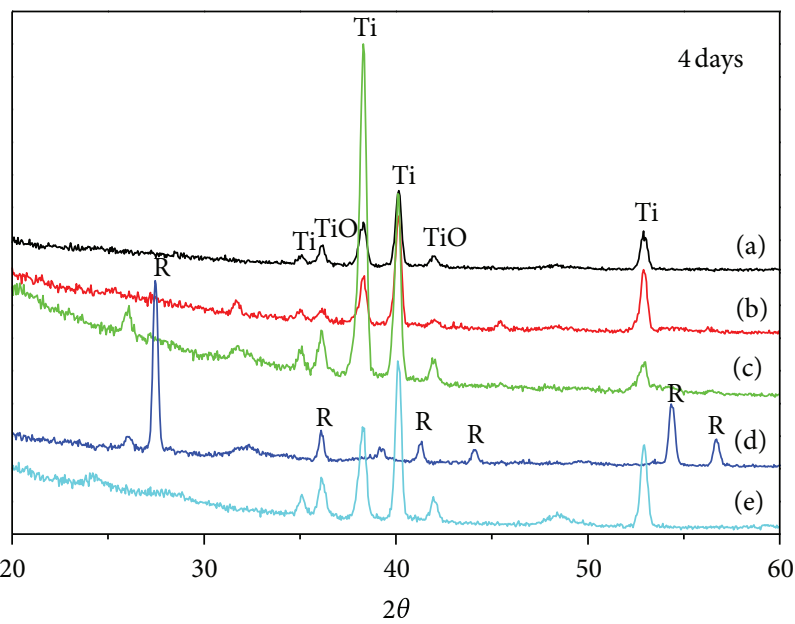

(b)

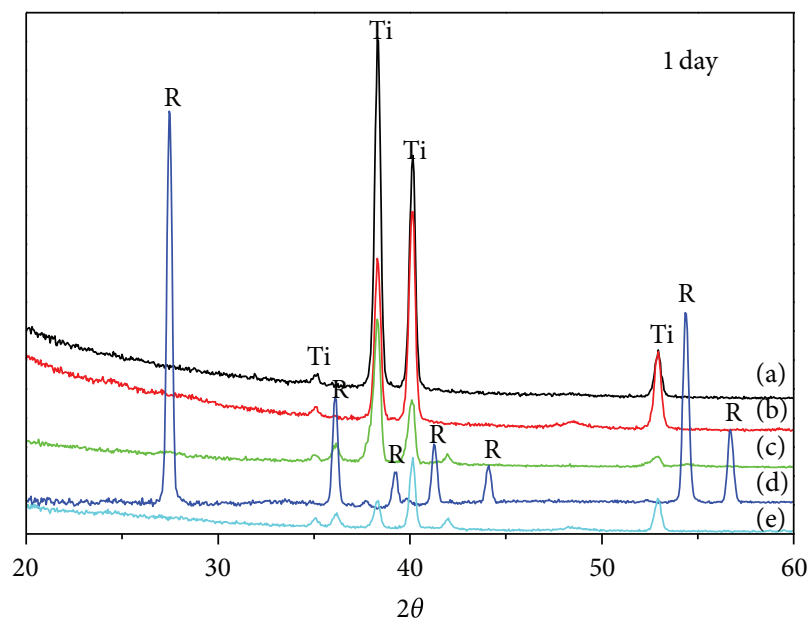

(c)

FIGURE 13: XRD patterns of group III soaked in PBS at $37^{\circ} \mathrm{C}$ for 1 day, 4 days, and 7 days. (a) HT200-NaOH, (b) HT300-NaOH, (c) HT500$\mathrm{NaOH}$, (d) HT800-NaOH, and (e) Ti-NaOH. (Ti: titanium, R: rutile, TiO: titanium oxide.)

immersion times. Regarding all other samples, Ti showed a similar spectrum as Ti-NaOH, and surface-treated Ti samples also showed similar spectra as $\mathrm{HT} 800-\mathrm{NaOH}$, but the intensity was different.

\section{Discussion}

In this study, the influence of commonly used surface modification methods on morphology, crystallinity, surface energy and water contact angle, and the bioactivity of pure Ti was analyzed. The results show that the differences found could be related to the potential bioactivity.

The morphology and the topography of the samples changed with heat treatment and sodium hydroxide treatment. The difference of HT samples was most pronounced on the $\mathrm{Ti}$ specimen heat treated at $800^{\circ} \mathrm{C}$. At this temperature, the rutile phase was achieved, and the surfaces also seemed to become rougher with HT, which has been show in previous studies [33, 34]. Extensive oxidation of the surfaces occurs at $800^{\circ} \mathrm{C}$, which results in the increase in hardness and also in the marked differences in surface properties. Originally, attempts were made to determine the oxide thickness as function of temperature, but the oxide thickness could not be determined with any accuracy. Such data would give important input to the understanding of the growth mechanisms and perhaps also on the connection to oxide crystallographic phase composition. Very little data on this topic can be found in the literature. Another drawback with present study and other studies is the lack of information about the actual surface charge as function of the surface modification technique. So far, no method has been proposed that can easily determine the charge; instead, the present investigation determined the surface energy and wettability.

The increased wettability with increased temperature was connected to the increase in surface energy, and this could improve the interaction between the implant surface and cells and proteins in vivo [35-37]. A decrease in water contact angle with increase of temperature treatment of the Ti was also shown in the testing. The surfaces treated at $800^{\circ} \mathrm{C}$ showed a formation of rutile, regardless of soaking in 


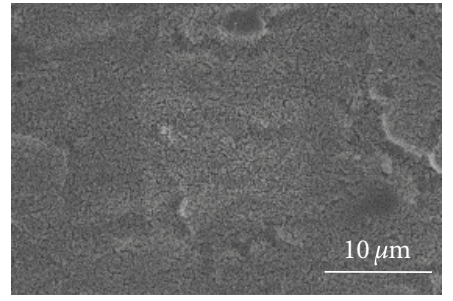

(a)

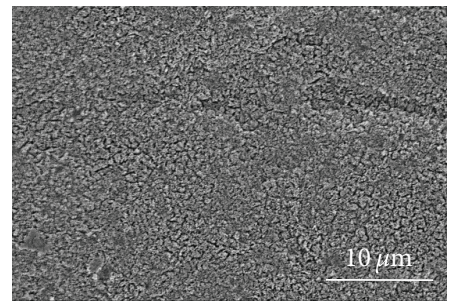

(d)

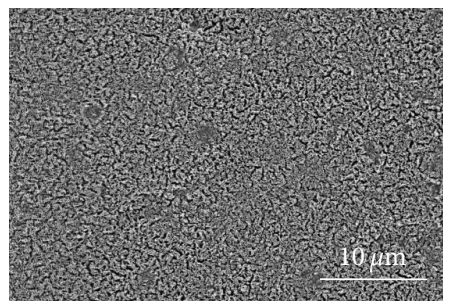

(g)

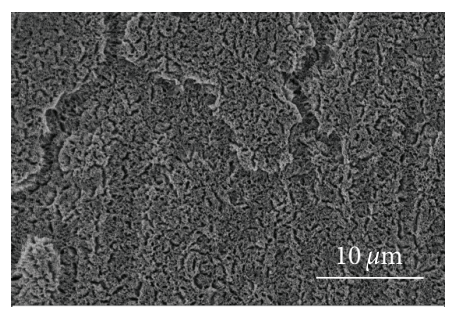

(j)

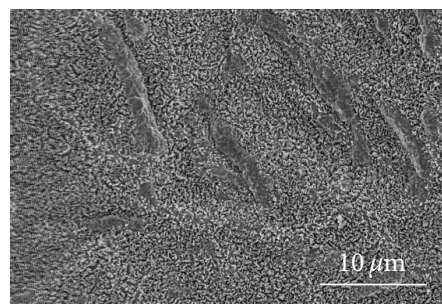

(m)

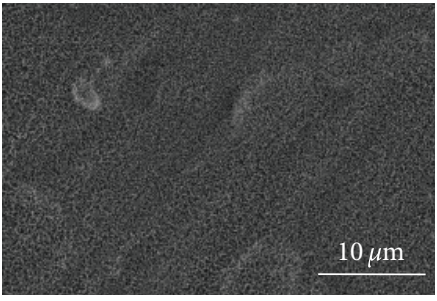

(b)

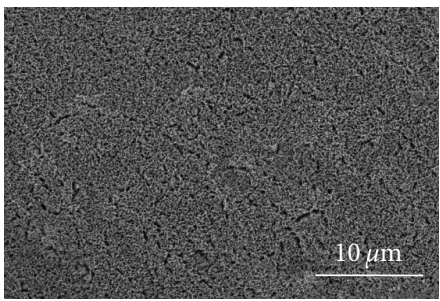

(e)

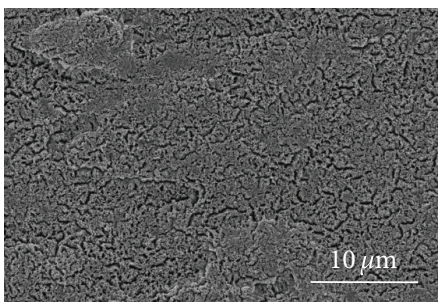

(h)

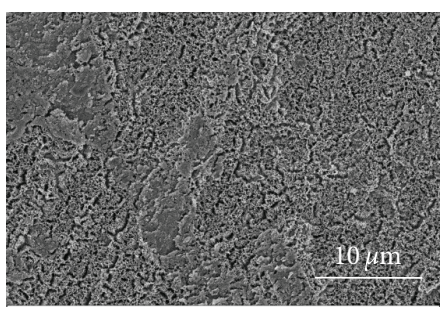

(k)

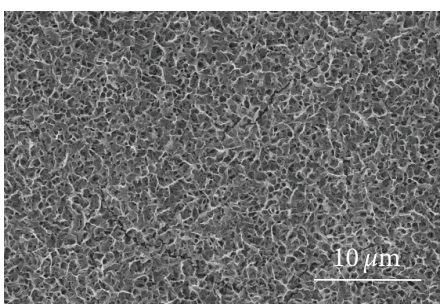

(n)

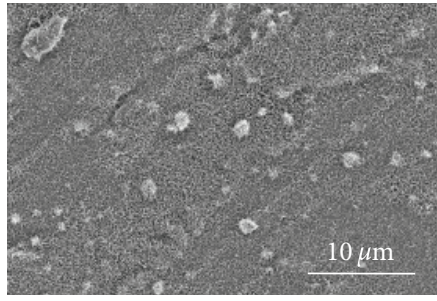

(c)

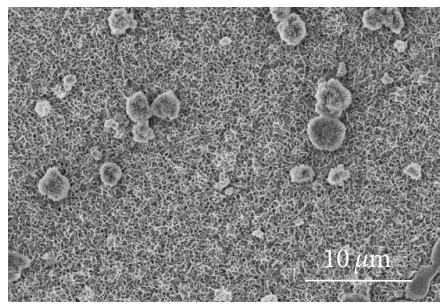

(f)

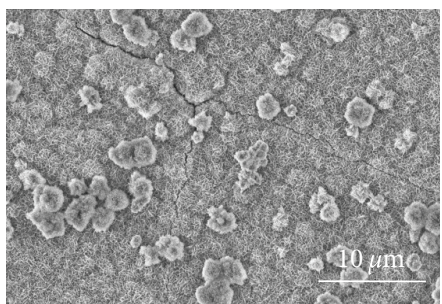

(i)

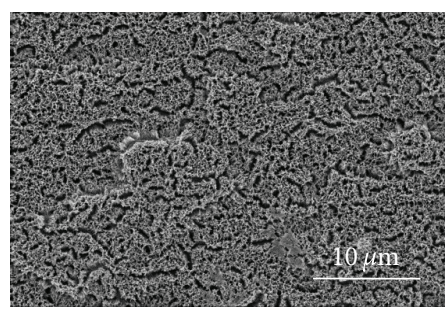

(l)

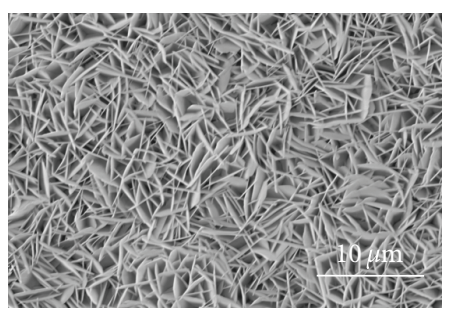

(o)

FIGURE 14: Ti subjected to $\mathrm{NaOH}$ soaking followed by HT (group IV) and subsequently soaked in PBS in PBS at $37^{\circ} \mathrm{C}$ for 1 day, 4 days, and 7 days. (a) Ti-NaOH 1 d, (b) Ti-NaOH 4 d, (c) Ti-NaOH 7 d (d) NaOH-HT200 1 d, (e) NaOH-HT200 4 d, (f) NaOH-HT200 7 d, (g) NaOH-HT300 1 d, (h) NaOH-HT300 4d, (i) NaOH-HT300 7 d, (j) NaOH-HT500 1 d, (k) NaOH-HT500 4 d, (l) NaOH-HT500 7 d, (m) $\mathrm{NaOH}-\mathrm{HT} 8001$ d, (n) NaOH-HT800 4 d, and (o) NaOH-HT800 7 d. 


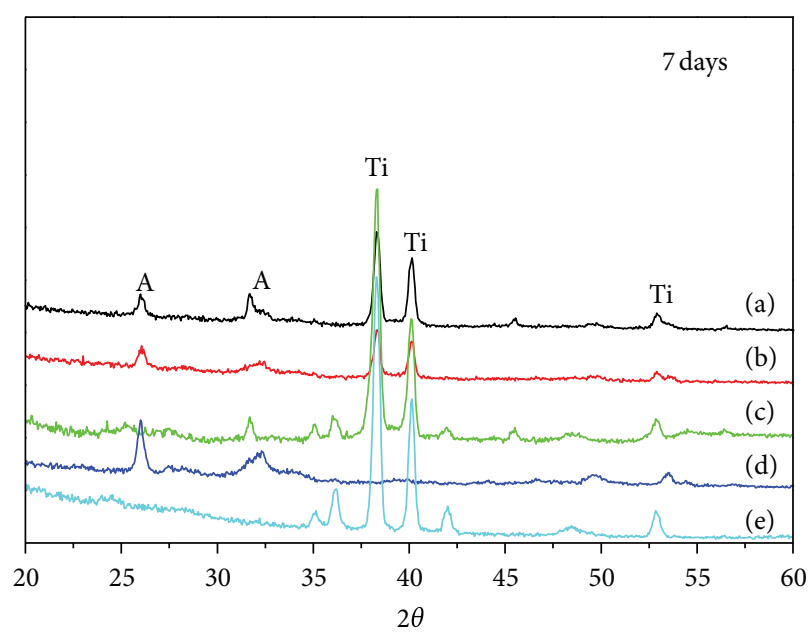

(a)

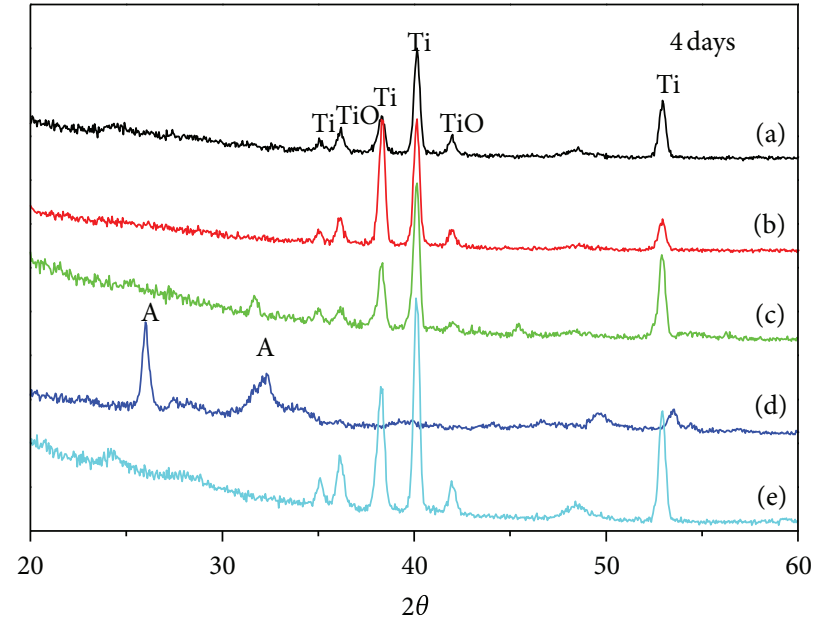

(b)

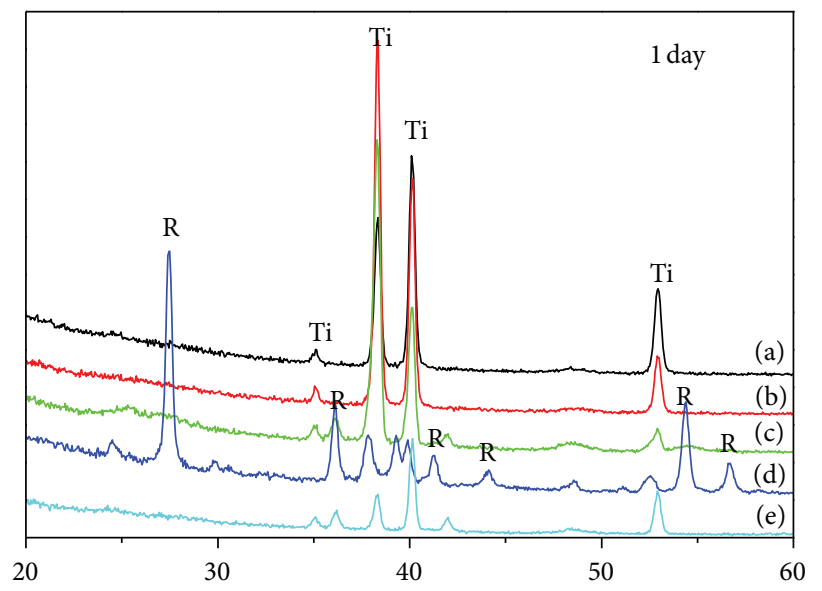

(c)

FIGURE 15: XRD patterns for group IV immersed in PBS for different time periods at $37^{\circ} \mathrm{C}$. (a) NaOH- HT200; (b) NaOH-HT300; (c) NaOHHT500; (d) NaOH-HT800; (e) Sodium hydroxide treated (5 M NaOH for $24 \mathrm{~h}$ ). (Ti: titanium, R: rutile, TiO: titanium oxide.)

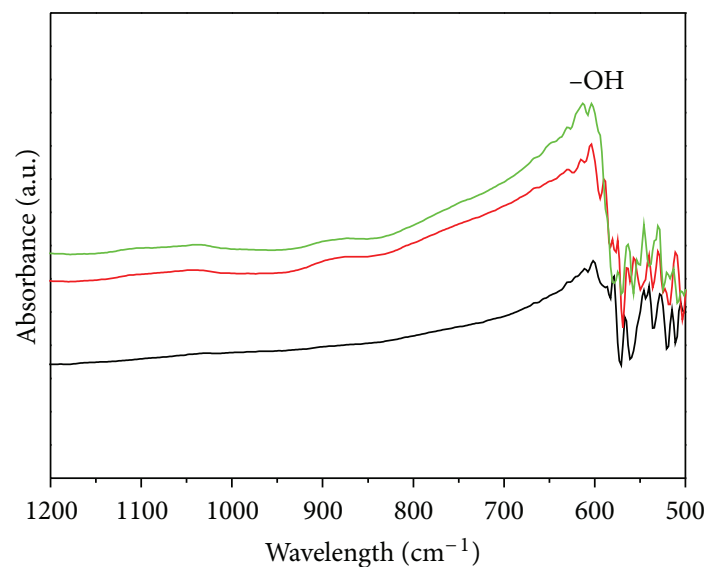

Ti-NaOH $7 \mathrm{~d} 37^{\circ} \mathrm{C}$
$-\mathrm{Ti}-\mathrm{NaOH} 4 \mathrm{~d} 37^{\circ} \mathrm{C}$
$-\mathrm{Ti}-\mathrm{NaOH} 1 \mathrm{~d} 37^{\circ} \mathrm{C}$

(a)

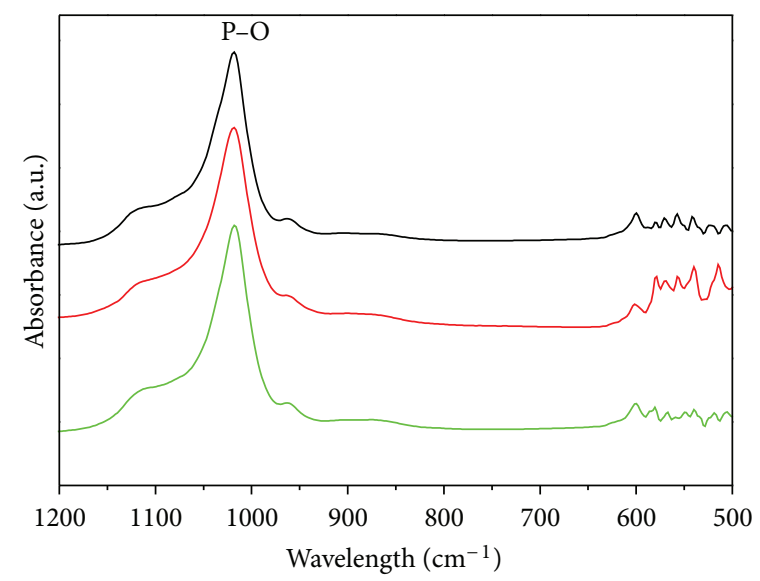

- $\mathrm{HT} 800-\mathrm{NaOH} 7 \mathrm{~d} 37^{\circ} \mathrm{C}$

- $\mathrm{HT} 800-\mathrm{NaOH} 4 \mathrm{~d} 37^{\circ} \mathrm{C}$

HT800- $\mathrm{NaOH} 1 \mathrm{~d} 37^{\circ} \mathrm{C}$

(b)

FIgURE 16: FTIR spectra of samples soaked in PBS for 1 day, 4 days, and 7 days. (a) Ti-NaOH $37^{\circ} \mathrm{C}$ and (b) $\mathrm{HT} 800-\mathrm{NaOH} 37^{\circ} \mathrm{C}$. 
$\mathrm{NaOH}$ or not. Heat treatment at $800^{\circ} \mathrm{C}$ shows a faster apatite formation compared to the other temperatures. This surface also had the lowest contact angle and the highest surface energies which could explain its superior apatite formation ability. The increase in bioactivity observed in this study is in agreement with previous works that have concluded that the surface energy, wettability, and topography are important for the capability to induce apatite formation [35]. The experiments also showed that sodium hydroxide treatment $(\mathrm{NaOH})$ of the $\mathrm{Ti}$ increases the surface energy compared to surfaces subject to only heat treatment. The increase in surface energy after $\mathrm{NaOH}$ treatment may explain why the bioactivity is higher on $\mathrm{NaOH}+\mathrm{HT}$ Ti as well as the obvious increase in number of $\mathrm{OH}$ group on the surface.

\section{Conclusions}

In this study, the effect of different treatments on the morphology, crystallinity, hardness, surface energy, and bioactivity was studied. The results showed that for the HT samples, the bioactivity and surface energy were highest for the $\mathrm{Ti}$ specimen treated at $800^{\circ} \mathrm{C}$. Sodium hydroxide treatment of the HT samples increased the surface energy and improved the bioactivity compared to Ti with only HT. Also, $\mathrm{NaOH}$ treatment followed by HT increased the bioactivity compared to only HT. The decrease in water contact angle and increase in surface energy could be due to the more porous surface structure after sodium hydroxide treatment. The results in this study confirmed that the wettability and surface energy are important factors for apatite formation. Low water contact angle and high surface energy of $\mathrm{Ti}$ surfaces were good for a fast HA deposition.

\section{Conflict of Interests}

The authors have declared that no conflict of interests exists.

\section{Acknowledgments}

This work was supported by BIOMATCELL, VINN Excellence Center of Biomaterials and Cell Therapy. The authors also thank Dr. Max Wolff from Department of Physics and Astronomy, Uppsala University, for his help with the contact angle measurements, and Dr. Shuanglin $\mathrm{Hu}$ from Department of Chemistry, Uppsala University, for his help with calculations of surface energy.

\section{References}

[1] L. Carlsson, T. Rostlund, B. Albrektsson, T. Albrektsson, and P. I. Brånemark, "Osseointegration of titanium implants," Acta Orthopaedica Scandinavica, vol. 57, no. 4, pp. 285-289, 1986.

[2] B. Kasemo, "Biocompatibility of titanium implants: surface science aspects," The Journal of Prosthetic Dentistry, vol. 49, no. 6, pp. 832-837, 1983.

[3] D. Bardos, "Titanium and Titanium alloys," in Encyclopedia of Medical and Dental Materials, D. William, Ed., pp. 360-365, Pergamon Press, Oxford, UK, 1990.
[4] J. Ellingsen and S. Lyngstadaas, Bioimplant Interface: Improving Biomaterials and Tissue Reactions, CRC Press, Boca Raton, Fla, USA, 2003.

[5] P. Layrolle, M. Stigter, and K. De Groot, "Biomimetic and electrolytic calcium phosphate coatings on titanium alloy: physicochemical characteristics and cell attachment," Biomaterials, vol. 25, no. 4, pp. 583-592, 2004.

[6] L. A. De Sena, M. C. De Andrade, A. M. Rossi, and G. A. De Soares, "Hydroxyapatite deposition by electrophoresis on titanium sheets with different surface finishing," Journal of Biomedical Materials Research, vol. 60, no. 1, pp. 1-7, 2002.

[7] A. Wennerberg, T. Albrektsson, C. Johansson, and B. Andersson, "Experimental study of turned and grit-blasted screwshaped implants with special emphasis on effects of blasting material and surface topography," Biomaterials, vol. 17, no. 1, pp. 15-22, 1996.

[8] M. Uchida, H. M. Kim, T. Kokubo, S. Fujibayashi, and T. Nakamura, "Structural dependence of apatite formation on titania gels in a simulated body fluid," Journal of Biomedical Materials Research A, vol. 64, no. 1, pp. 164-170, 2003.

[9] X.-X. Wang, S. Hayakawa, K. Tsuru, and A. Osaka, "A comparative study of in vitro apatite deposition on heat-, $\mathrm{H}_{2} \mathrm{O}_{2}$-, and $\mathrm{NaOH}$-treated titanium surfaces," Journal of Biomedical Materials Research, vol. 54, no. 2, pp. 172-178, 2001.

[10] T. Kokubo and H. Takadama, "How useful is SBF in predicting in vivo bone bioactivity?" Biomaterials, vol. 27 , no. 15 , pp. 2907-2915, 2006.

[11] P. Zhu, Y. Masuda, and K. Koumoto, "The effect of surface charge on hydroxyapatite nucleation," Biomaterials, vol. 25, no. 17, pp. 3915-3921, 2004.

[12] T. Kokubo, F. Miyaji, H. M. Kim, and T. Nakamura, "Spontaneous formation of bonelike apatite layer on chemically treated titanium metals," Journal of the American Ceramic Society, vol. 79, no. 4, pp. 1127-1129, 1996.

[13] D. K. Pattanayak, S. Yamaguchi, T. Matsushita, and T. Kokubo, "Nanostructured positively charged bioactive $\mathrm{TiO}_{2}$ layer formed on Ti metal by $\mathrm{NaOH}$, acid and heat treatments," Journal of Materials Science, vol. 22, no. 8, pp. 1803-1812, 2011.

[14] K. Kawanabe, K. Ise, K. Goto et al., "A new cementless total hip arthroplasty with bioactive titanium porous-coating by alkaline and heat treatment: average 4.8-year results," Journal of Biomedical Materials Research B, vol. 90, no. 1, pp. 476-481, 2009.

[15] H. Nygren, P. Tengvall, and I. Lundstrom, "The initial reactions of $\mathrm{TiO}_{2}$ with blood," Journal of Biomedical Materials Research, vol. 34, pp. 487-492, 1997.

[16] B. Wälivaara, A. Askendal, I. Lundström, and P. Tengvall, "Blood protein interactions with titanium surfaces," Journal of Biomaterials Science, vol. 8, pp. 41-48, 1996.

[17] S. G. Steinemann, "Titanium-the material of choice?" Periodontology 2000, vol. 17, no. 1, pp. 7-21, 1998.

[18] D. M Brunette, P. Tengvall, M. Textor, and P. Thomsen, Titanium in Medicine, Springer, New York, NY, USA, 2001.

[19] R. Rohanizadeh, M. Al-Sadeq, and R. Z. LeGeros, "Preparation of different forms of titanium oxide on titanium surface: effects on apatite deposition," Journal of Biomedical Materials Research A, vol. 71, no. 2, pp. 343-352, 2004.

[20] X. X. Wang, W. Yan, S. Hayakawa, K. Tsuru, and A. Osaka, "Apatite deposition on thermally and anodically oxidized titanium surfaces in a simulated body fluid," Biomaterials, vol. 24, no. 25, pp. 4631-4637, 2003. 
[21] M. Uchida, H. M. Kim, T. Kokubo, S. Fujibayashi, and T. Nakamura, "Effect of water treatment on the apatite-forming ability of $\mathrm{NaOH}$-treated titanium metal," Journal of Biomedical Materials Research, vol. 63, no. 5, pp. 522-530, 2002.

[22] X. X. Wang, S. Hayakawa, K. Tsuru, and A. Osaka, "Bioactive titania gel layers formed by chemical treatment of Ti substrate with a $\mathrm{H}_{2} \mathrm{O}_{2} / \mathrm{HCl}$ solution," Biomaterials, vol. 23, no. 5, pp. 1353-1357, 2002.

[23] B. Yang, M. Uchida, H. M. Kim, X. Zhang, and T. Kokubo, "Preparation of bioactive titanium metal via anodic oxidation treatment," Biomaterials, vol. 25, no. 6, pp. 1003-1010, 2004.

[24] J. M. Wu, S. Hayakawa, K. Tsuru, and A. Osaka, "Low-temperature preparation of anatase and rutile layers on titanium substrates and their ability to induce in vitro apatite deposition," Journal of the American Ceramic Society, vol. 87, no. 9, pp. 1635-1642, 2004.

[25] M. H. Lee, I. S. Park, K. S. Min et al., "Evaluation of in vitro and in vivo tests for Surface-modified Titanium by $\mathrm{H}_{2} \mathrm{SO}_{4}$ and $\mathrm{H}_{2} \mathrm{O}_{2}$ Treatment," Metals and Materials International, vol. 13, no. 2, pp. 109-115, 2007.

[26] X. Lu, Y. Wang, X. Yang et al., "Spectroscopic analysis of titanium surface functional groups under various surface modification and their behaviors in vitro and in vivo," Journal of Biomedical Materials Research A, vol. 84, no. 2, pp. 523-534, 2008.

[27] F. Lindberg, J. Heinrichs, F. Ericson, P. Thomsen, and H. Engqvist, "Hydroxylapatite growth on single-crystal rutile substrates," Biomaterials, vol. 29, no. 23, pp. 3317-3323, 2008.

[28] A. Sugino, C. Ohtsuki, K. Tsuru et al., "Effect of spatial design and thermal oxidation on apatite formation on Ti-15Zr-4Ta4Nb alloy," Acta Biomaterialia, vol. 5, no. 1, pp. 298-304, 2009.

[29] Y. J. Lee, D. Z. Cui, H. R. Jeon et al., "Surface characterisation of thermally treated titanium surfaces," Journal of Periodontal \& Implant Science, vol. 42, pp. 81-87, 2012.

[30] J. M. Schakenraad, H. J. Busscher, C. R. H. Wildevuur, and J. Arends, "The influence of substratum surface free energy on growth and spreading of human fibroblasts in the presence and absence of serum proteins," Journal of Biomedical Materials Research, vol. 20, no. 6, pp. 773-784, 1986.

[31] M. E. Schrader, "On adhesion of biological substances to low energy solid surfaces," Journal of Colloid And Interface Science, vol. 88, no. 1, pp. 296-297, 1982.

[32] E. C. Combe, B. A. Owen, and J. S. Hodges, "A protocol for determining the surface free energy of dental materials," Dental Materials, vol. 20, no. 3, pp. 262-268, 2004.

[33] M. Lindgren, M. Åstrand, U. Wiklund, and H. Engqvist, "Investigation of boundary conditions for biomimetic HA deposition on titanium oxide surfaces," Journal of Materials Science, vol. 20, no. 7, pp. 1401-1408, 2009.

[34] Y.-J. Lee, D.-Z. Cui, H.-R. Jeon, H.-J. Chung, and Y.-J. Kim, "Surface characteristics of thermally treated titanium surfaces," Journal of Periodontal and Implant Science, vol. 42, no. 3, pp. 81-87, 2012.

[35] B. Feng, J. Y. Chen, S. K. Qi, L. He, J. Z. Zhao, and X. D. Zhang, "Characterization of surface oxide films on titanium and bioactivity," Journal of Materials Science, vol. 13, no. 5, pp. 457-464, 2002.

[36] M. E. Schrader, "On adhesion of biological substances to low energy solid surfaces," Journal of Colloid And Interface Science, vol. 88, no. 1, pp. 296-297, 1982.
[37] J. M. Schakenraad, H. J. Busscher, C. R. H. Wildevuur, and J. Arends, "The influence of substratum surface free energy on growth and spreading of human fibroblasts in the presence and absence of serum proteins," Journal of Biomedical Materials Research, vol. 20, no. 6, pp. 773-784, 1986. 

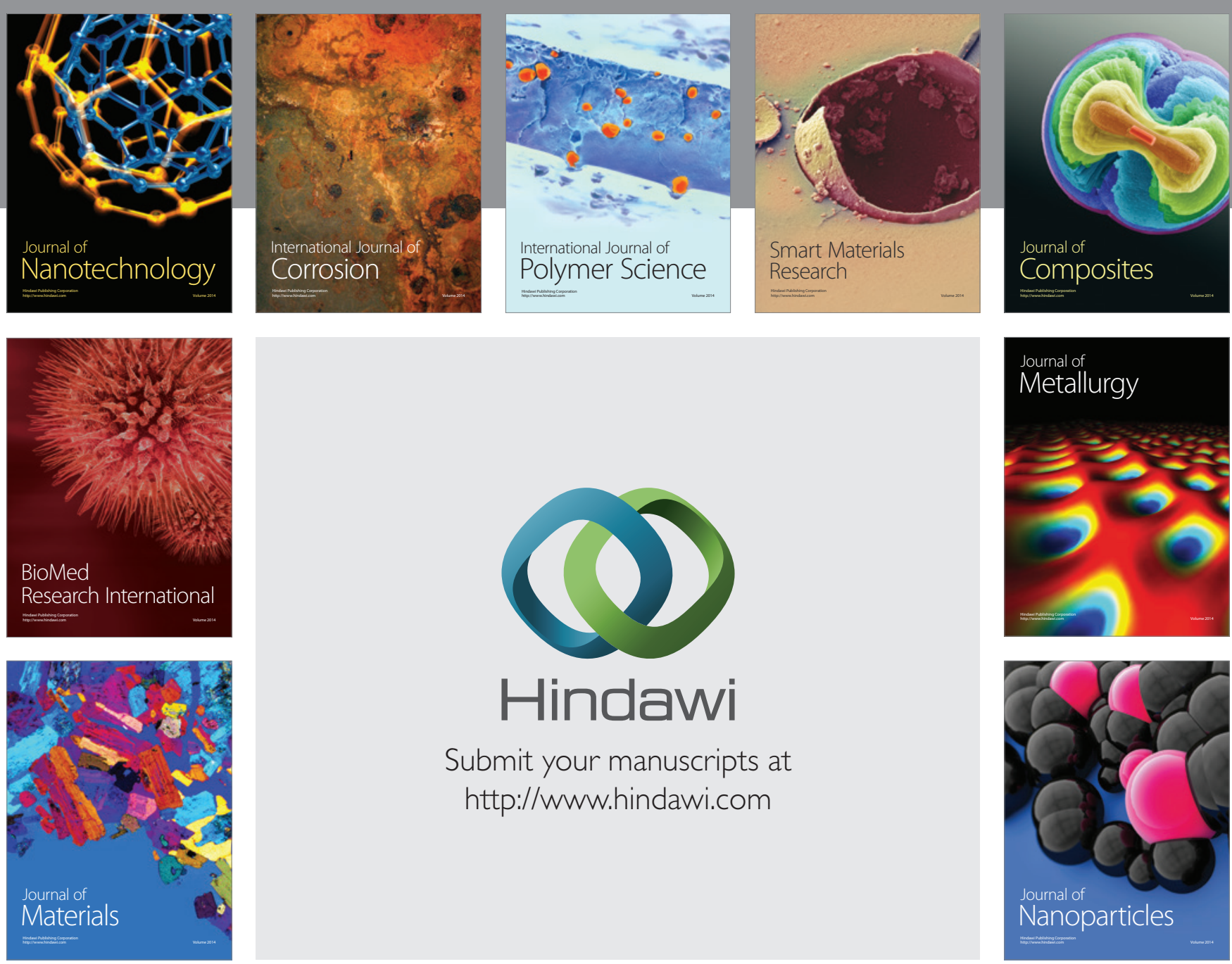

Submit your manuscripts at http://www.hindawi.com
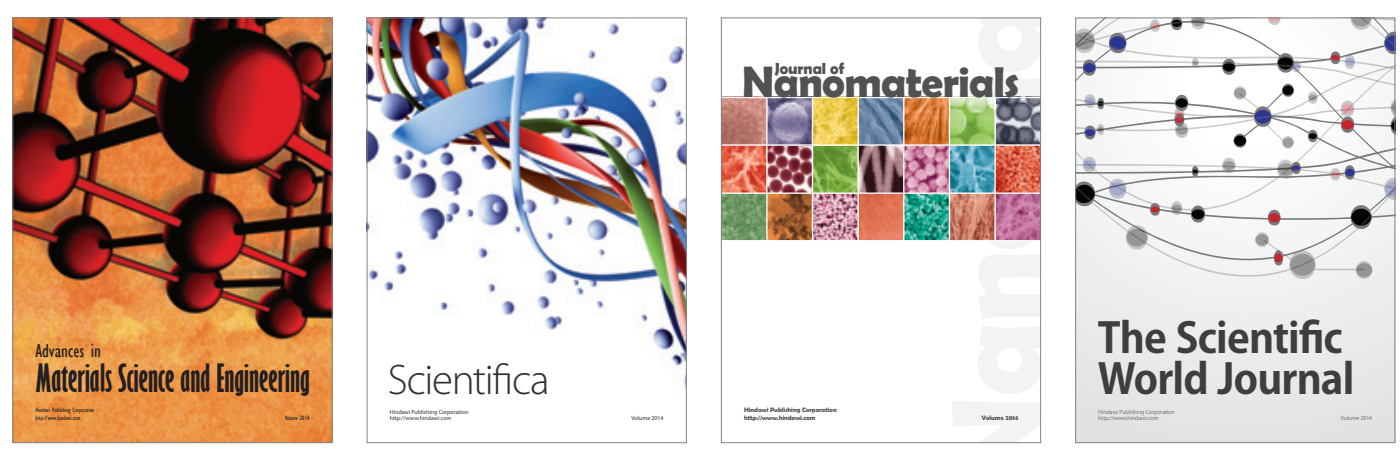

\section{The Scientific World Journal}
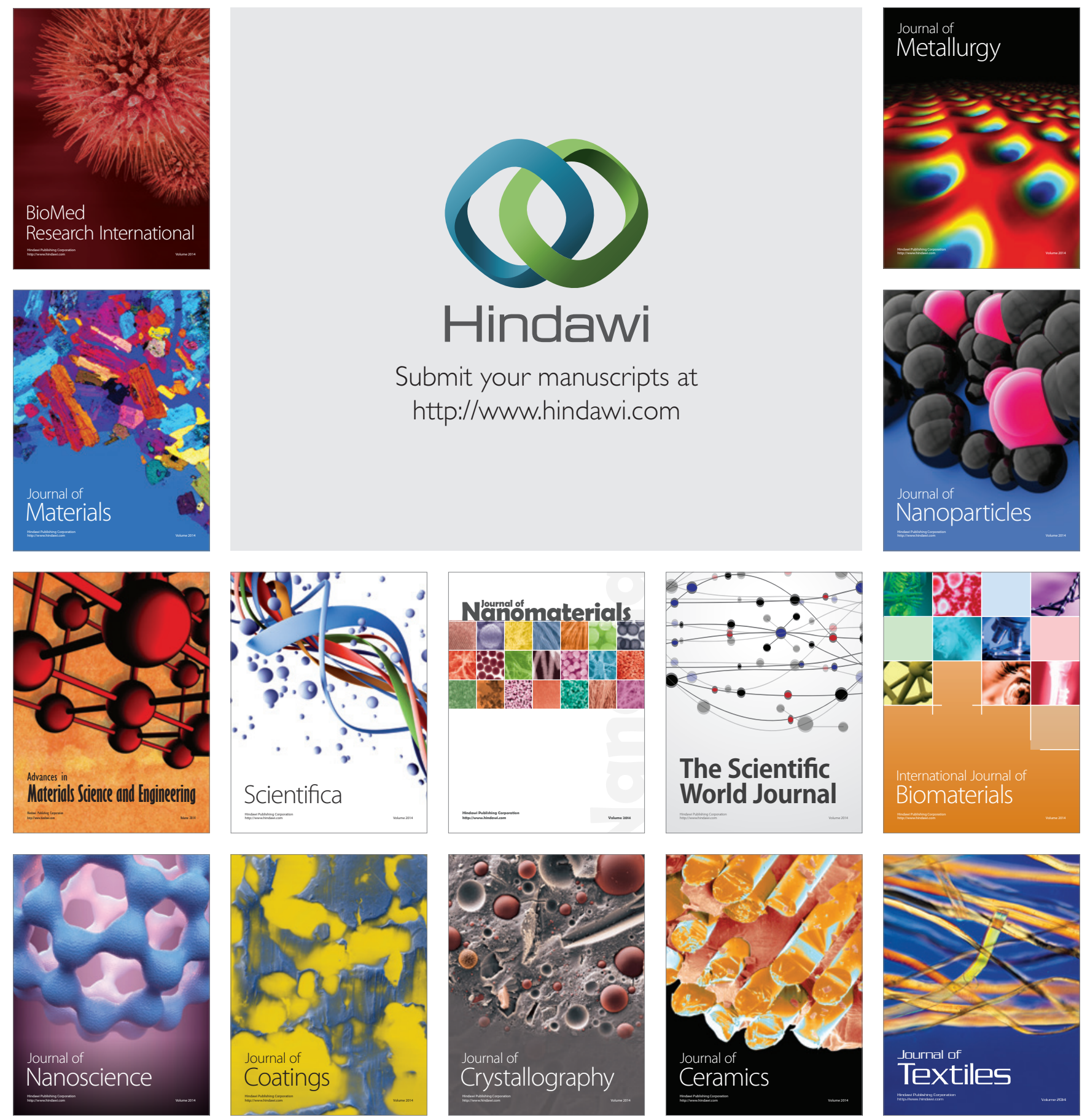